\title{
Thermodynamics of Multicomponent Amorphous Alloys: Theories and Experiment Comparison
}

\author{
B.B. Khina ${ }^{1}$, G.G. Goranskiy ${ }^{2}$ \\ ${ }^{1}$ Physico-Technical Institute, National Academy of Sciences of Belarus, \\ 10, Kuprevich Street, Minsk, 220141, Belarus \\ ${ }^{2}$ Scientific and Technological Park "Polytechnic", Belarusian National Technical University, \\ 65, Nezavisimosti Avenue, Minsk, 220027, Belarus \\ * Corresponding author. Tel.: +375(293)02 9387.E-mail: khina_brs@mail.ru
}

\begin{abstract}
On the basis of the existing thermodynamic theories of the amorphous matter (semi-empirical Miedema model and Shao theory), the integral (enthalpy and Gibbs energy) and partial molar characteristics of a multicomponent iron-based amorphous alloy are determined. It is demonstrated that for quaternary alloy $\mathrm{Fe}-7.3 \% \mathrm{Si}-14.2 \% \mathrm{~B}-8.26$ \% Ni these approaches give substantially different values of Gibbs energy and enthalpy at elevated temperatures, however, the difference between the values calculated by these two models becomes insignificant at a room temperature. For the first time, the chemical potential and partial molar enthalpy of iron (the base element of the amorphous phase) are compared with the data obtained from electrochemical measurements. It is demonstrated that the existing thermodynamic models give incorrect description of the partial molar parameters of the components of amorphous phase.
\end{abstract}

\section{Keywords}

Amorphous alloys; chemical potential; enthalpy; Gibbs energy; Miedema model; partial molar enthalpy; Shao theory.

(C) B.B. Khina, G.G. Goranskiy, 2017

\section{Introduction}

The amorphous alloys or metallic glasses have unique properties, in particular, high and stable elasticity, good corrosion resistance in various media, low coefficient of friction and high wear resistance, and thus are widely used as materials and coatings. Bulk amorphous alloys are produced by quenching the metal melt (rapid cooling up to room temperature) by melt spinning technique - extrusion of the molten alloy jet on the rotating water-cooled drum or passing it between two rollers [1]. Powders of amorphous alloys are prepared by mechanical alloying (MA) intensively milling a powder mixture of the initial components (metals and nonmetals) in vibration and planetary ball mills, attritors and other similar devices [2]. There is also a technique for producing thick amorphous ribbons as a result of solid phase diffusion in a binary multi-layer thin-film systems of the type (Fe, Co, $\mathrm{Ni})-(\mathrm{Ti}, \mathrm{Zr}, \mathrm{Hf}), \mathrm{Au}-\mathrm{La}, \mathrm{Cu}-\mathrm{Zr}$, etc. under long-duration annealing at a temperature below the point of crystallization onset of the amorphous alloy [3].
To produce parts made of amorphous alloys, ribbons or wire obtained after spinning and powders after MA are compacted by isostatic pressing or sintering under pressure at a temperature below crystallization point. Amorphous powders are used for spraying coatings onto the fast wearing parts of machines.

To develop new multicomponent amorphous alloys and define their field of temperature stability, it is important to know their thermodynamic characteristics. The enthalpy of formation of amorphous alloys is usually assessed by semiempirical Miedema model (A.R. Miedema), which is used to analyze the amorphization ability of supercooled melts under rapid quenching [4]. However, for triple amorphous alloys, this model gives a great contrast to the experimental values of enthalpy $\mathrm{H}_{\text {exp. }}$. Thus, according to [5], relative deviation $\mid \mathrm{H}_{\text {Miedema }}-\mathrm{H}_{\text {exp }} / / \mathrm{H}_{\text {exp }}$ for $\mathrm{Fe}-\mathrm{Ni}-\mathrm{V}$ alloys is $18 \%$, for $\mathrm{Fe}-\mathrm{Ni}-\mathrm{Zr}$ system $-14 \%$, for $\mathrm{Ni}-\mathrm{Cu}-\mathrm{Al}-$ $60 \%$, for $\mathrm{Cu}-\mathrm{Ag}-\mathrm{Au}$ - from 14 to $82 \%$, for $\mathrm{Au}-\mathrm{Sb}-\mathrm{Zn}$ - from 17 to $29 \%$, for $\mathrm{Y}-\mathrm{Cu}-\mathrm{Mg}-$ from 14 to $43 \%$, for $\mathrm{Pb}-\mathrm{Sn}-\mathrm{Sb}$ - from 29 to $115 \%$, 
for $\mathrm{Pb}-\mathrm{Sn}-\mathrm{Zn}$ - from 44 to $57 \%$, for the alloys of $\mathrm{Cu}-\mathrm{Pd}-\mathrm{Si}$ - from 24 to $50 \%$.

However, there is a simple electrochemical method for measuring the chemical potential difference of the base metal between a single-phase amorphous alloy and a pure metal electrode $\left(\Delta \mu_{\mathrm{M}}\right)$ by instantaneous fixing of electromotive force (IFEMF) $[6,7]$. It has been used by us for multicomponent amorphous-crystalline iron-based alloys, and a theoretical method to determine the chemical potential of iron in the amorphous phase has been developed on the basis of the results of experimental measurements of the multiphase alloy [8].

It should be noted that in the literature the theory has never been compared to experiment for the partial molar quantities of amorphous alloys (chemical potential and partial molar enthalpy of components). Moreover, based on the Miedema model and other thermodynamic theories of amorphous state, these quantities have not been previously calculated.

In connection with the above, the aim of this study is to compare the data on the chemical potential of iron in the amorphous phase $\mu_{\mathrm{Fe}}^{(\mathrm{am})}$ and its partial molar enthalpy $h_{\mathrm{Fe}}^{(\mathrm{am})}$ obtained from experiments with the predictions of the existing theories. For this it is necessary first of all to determine the theoretical values of the partial molar elements in the amorphous phase.

\section{Materials and Methods}

The compositions of the alloys which were used in experimental measurements and theoretical calculations are the following (wt \%.): $\mathrm{Fe}-7.3 \% \mathrm{Si}-$ $14.2 \%$ B $-8.26 \% \mathrm{Ni}$ (alloy 1) и $\mathrm{Fe}-0.32 \% \mathrm{Si}-$ $4.8 \% \mathrm{~B}-6.68 \% \mathrm{Ni}-2.42 \%$ Co $-8.88 \% \mathrm{Cr}-$ $6.42 \%$ Mo (alloy 2). After quenching from liquid state by spinning technique the complete amorphization in them was not achieved: the proportion of the amorphous phase was $78 \%$ in alloy 1 and $82 \%$ in alloy 2. Therefore, they were subjected to MA in the attritor, which resulted in dissolution of crystalline inclusions (iron borides and intermetallides) in an amorphous matrix, whereby the proportion of the amorphous phase increased up to $98 \%$ in both alloys [8]. Electrochemical measurements of $\Delta \mu_{\mathrm{Fe}}$ value by IFEMF method for multiphase amorphous-crystalline alloys data at different MA times were performed in an electrochemical cell using the solution of potassium chloride and iron sulfate in an anhydrous alcohol as an electrolyte [6, 7]

$$
-\alpha-\mathrm{Fe}\left|\mathrm{KCl}, \mathrm{Fe}_{2}\left(\mathrm{SO}_{4}\right)_{3}, \mathrm{C}_{2} \mathrm{H}_{5} \mathrm{OH}\right|\langle\mathrm{Fe}\rangle_{\text {alloy }}{ }^{+} \text {, }
$$

where $\alpha$-Fe is a cathode made of pure ARMCO-iron, $\langle\mathrm{Fe}\rangle_{\text {alloy }}{ }^{+}$is an anode the role of which is played by iron in amorphous-crystalline alloy.

On the basis of the measured $\Delta \mu_{\mathrm{Fe}}$ values and previously developed theory [8] there were calculated $\mu_{\mathrm{Fe}}^{(\mathrm{am})}$ and $h_{\mathrm{Fe}}^{(\mathrm{am})}$ values for alloys 1 and 2 which appeared to be dependent on the MA time; the latter may be caused by a change in atomic-cluster structure of the amorphous phase as a result of periodic plastic deformation under MA.

\section{Theoretical Study}

\section{Thermodynamic Miedema model for amorphous phase}

In assessing the enthalpy of crystalline, liquid and amorphous phases, for which there is no data in the reference literature, as well as for predicting the range of compositions of amorfizing alloys the semiempirical Miedema model is used, which was developed for binary alloys [9-11] and generalized for ternary and multicomponent systems [4]. Under this model, the change in enthalpy $\Delta H_{\text {chem }}$ in the formation of the phase of the elements is expressed as

$$
\Delta H_{\text {chem }}=\sum_{j>i=1}^{N} x_{i} x_{j}\left(x_{j}^{\mathrm{s}} \Delta H_{i \text { in } j}^{\text {chem }}+x_{i}^{\mathrm{s}} \Delta H_{j \text { in } i}^{\text {chem }}\right) f_{i j},
$$

here $x_{i}$ and $x_{j}$ are mole fractions of components $i$ and $j$, $i \neq j, N$ is the number of components, $x_{i}^{\mathrm{s}}$ is atoms concentration of $i$-th kind at the border of Wigner-Seitz cells (Wigner-Seitz), $\Delta H_{i \text { in } j}^{\text {chem }}$ is enthalpy of dissolution of element $i$ in $j$.

For each pair $i-j$ values $x_{i}^{\mathrm{s}}$ and $x_{j}^{\mathrm{s}}$ are defined as

$$
x_{i}^{\mathrm{s}}=x_{i} V_{i}^{2 / 3} /\left(x_{i} V_{i}^{2 / 3}+x_{j} V_{j}^{2 / 3}\right), \quad x_{j}^{\mathrm{s}}=1-x_{i}^{\mathrm{s}},
$$

where $V_{i}$ is molar volume of $i$-th element, the values of which for some substances are adjusted according to the type of crystal lattice [12].

Parameter $f_{i j}$ included in formula (1) has the form

$$
f_{i j}=1+\gamma\left(x_{i}^{\mathrm{s}}+x_{j}^{\mathrm{s}}\right)^{2} \text {, }
$$

where for the amorphous state $\gamma=5$ [10].

Quantities $\Delta H_{i \text { in } j}^{\text {chem }}$ included in expression (1) are determined in the form [12]

$$
\begin{aligned}
\Delta H_{i \text { in } j}^{\text {chem }} & =\frac{2 P_{i j} V_{i}^{2 / 3}}{n_{i}^{-1 / 3}+n_{j}^{-1 / 3}}\left[-\left(\varphi_{i}^{*}-\varphi_{j}^{*}\right)^{2} e+\right. \\
& \left.+\frac{Q}{P_{i j}}\left(n_{i}^{1 / 3}-n_{j}^{1 / 3}\right)^{2}-\frac{R}{P_{i j}}\right],
\end{aligned}
$$


where $e$ is an elementary electric charge (electron charge), $\varphi_{i}^{*}$ is electronegativity parameter for $i$-th component, $n_{i}$ is electron density parameter at the boundary of the Wigner-Seitz cell, $P_{i j}$ and $R / P_{i j}$ are numerical parameters, depending on the nature of the pair of elements $i-j$, value $Q / P_{i j}=9.4$ for all substances.

The Miedema model uses specific value dimensions, which like in the original [12], are given in the English notation: $\left[V_{i}\right]=\mathrm{cm}^{3},\left[R / P_{i j}\right]=\mathrm{V}^{2} \mathrm{e}$, $\left[n_{i}\right]=$ d.u., $\quad\left[\varphi_{i}^{*}\right]=\mathrm{V}, \quad\left[Q / P_{i j}\right]=\mathrm{V}^{2}$ e(d.u. $)^{-2 / 3}, \quad\left[P_{i j}\right]=$ $=\mathrm{V}^{-1} \mathrm{~cm}^{-2}$ (d.u. $)^{-1 / 3}$, where $\mathrm{V} \equiv$ Volt,$e$ is electron charge, $\mathrm{cm} \equiv \mathrm{cm}$, d.u. (density unit) is electron density unit: 1 d.u. $\approx 6 \cdot 10^{22} \mathrm{~cm}^{-3}$ [13]. Then from formula (1.74) it is seen that factor $e$ at item $\left(\varphi_{i}^{*}-\varphi_{j}^{*}\right)^{2}$ is written only to meet the balance of the dimensions. In expression (1.74) value $\Delta H_{i \text { in } j}^{\text {chem }}$ has dimension $\mathrm{eV}$ (electron-volt), i.e. it is determined per 1 atom and for translation into $\mathrm{J} / \mathrm{mol}$ we use the conversion factor: $1 \mathrm{~J} / \mathrm{mol}=$ $=1.6021 \cdot 10^{-19} \cdot N_{A}=96.494 \cdot 10^{3} \mathrm{eV}$, where $N_{A}$ is Avogadro number. Values of all the parameters included in formula (4) for different pairs of elements are given in $[12,14]$.

Since for amorphous phases, the standard state for pure components is a liquid one [9], the integral enthalpy is written as

$$
H_{\mathrm{am}}=\sum_{i=1}^{N} x_{i} H_{i}^{\text {liq }}+\Delta H_{\text {chem }} .
$$

Here $H_{i}^{\text {liq }}$ is enthalpy of a pure $i$-th component in liquid state, which is defined as a polynomial by temperature degrees

$$
H_{i}^{\mathrm{liq}}=a_{i}-c_{i} T-\sum_{n}(n-1) d_{i, n} T^{n}+H_{i}^{\mathrm{SER}},
$$

where $H_{i}^{\mathrm{SER}}=H_{i}(T=298)-H_{i}(T=0)$ is a standard value (SER = standard element reference); values of coefficients $a_{i}, c_{i}, d_{i, n}$ and the number of members $n$ in the polynomial are given in the database (DB) SGTE [15].

To calculate Gibbs energy of the amorphous phase

$$
G_{\mathrm{am}}=H_{\mathrm{am}}-T S_{\mathrm{am}}
$$

you need to know its entropy $S_{\text {am }}$.

As noted above, the standard state for the pure components in this situation is a liquid one, thus the entropy of the amorphous phase can be written as

$$
S_{\mathrm{am}}=\sum_{i=1}^{N} x_{i} S_{i}^{\text {liq }}+S_{\sigma}+S_{\mathrm{id}}, \quad S_{\mathrm{id}}=-R \sum_{i=1}^{N} x_{i} \ln x_{i},
$$

where $S_{\sigma}$ is entropy of atomic size mismatch (mismatch entropy), inherent only in amorphous bodies, $S_{\mathrm{id}}$ is perfect mixing entropy.

In expression (8), standard entropy of the $i$-th element in liquid state $S_{i}^{\text {liq }}$ is determined by the DB SGTE [15] as a polynomial

$$
S_{i}^{\text {liq }}=-b_{i}-c_{i}-c_{i} \ln T-\sum_{n} n d_{i, n} T^{n-1},
$$

and the entropy of atomic size mismatch $S_{\sigma}$ is related to the atoms diameters $d$ by the following formulas $[16,17]$ :

$$
\begin{gathered}
S_{\sigma}=R\left\{1.5\left(\zeta^{2}-1\right) y_{1}+1.5(\zeta-1)^{2} y_{2}-\right. \\
\left.-[(\zeta-1)(\zeta-3) / 2+\ln \zeta]\left(1-y_{3}\right)\right\}, \\
y_{1}=\left(1 / \sigma_{3}\right) \sum_{j \geq i=1}^{N}\left(d_{i}+d_{j}\right)\left(d_{i}-d_{j}\right)^{2} x_{i} x_{j}, \\
y_{2}=\left(\sigma_{2} / \sigma_{3}^{2}\right) \sum_{j \geq i=1}^{N} d_{i} d_{j}\left(d_{i}-d_{j}\right)^{2} x_{i} x_{j}, \\
y_{3}=\sigma_{2}^{3} / \sigma_{3}^{2}, \quad \sigma_{n}=\sum_{i=1}^{N} x_{i} d_{i}{ }^{n}, \quad n=2,3,
\end{gathered}
$$

where $\zeta=1 /(1-\xi)$; for dense chaotic packing of spherical particles $\xi=0.64$.

Thus, formulas (1) - (11) provide a complete description of the integral thermodynamic parameters of the amorphous phase (enthalpy, Gibbs free energy and entropy) within the semiempirical Miedema model.

\section{Thermodynamic model of stabilizing the amorphous phase}

In his works [18-20] G. Shao proposed the theory of stabilizing the amorphous phase in reference to the melt, which uses an analogy with the thermodynamic description of the magnetic transition in CALPHAD approach used to calculate the alloy state diagrams. A change in Gibbs energy $\Delta G_{\mathrm{liq} \rightarrow \mathrm{am}}$ in the conversion of supercooled liquid (liq) into amorphous phase (am) is expressed as

$$
\Delta G_{\mathrm{liq} \rightarrow \mathrm{am}}=R T \ln (1+\alpha) f(\tau), \quad \tau=T / T_{\mathrm{g}} .
$$

In formula (12) $\alpha$ is a stabilization parameter characterizing the increase in the thermodynamic stability of amorphous alloy compared with the supercooled liquid at $T<T_{\mathrm{g}}$, where $T_{\mathrm{g}}$ is temperature of glass transition or Kauzmann temperature (W. Kauzmann) which depends on the composition; for pure metals $T_{\mathrm{g}}=(0.25-0.64) T_{\mathrm{m}}$, where $T_{\mathrm{m}}$ is a melting point. 
Function $f(\tau)$ is defined as

$$
\begin{gathered}
f=\left\{\begin{array}{c}
1+a_{1} \tau^{-1}+a_{2} \tau^{3}+a_{3} \tau^{9}+a_{4} \tau^{15} \text { при } \tau \leq 1 ; \\
b_{1} \tau^{-5}+b_{2} \tau^{-15}+b_{3} \tau^{-25} \text { при } \tau>1 ;
\end{array}\right. \\
a_{1}=-0.9917, \quad a_{2}=-0.1117 \\
b_{1}=-0.1054, b_{2}=-3.3474 \cdot 10^{-3}, b_{3}=-7.0296 \cdot 10^{-4} .
\end{gathered}
$$

Since

$$
H=G+T S=G-T\left(\frac{\partial G}{\partial T}\right)_{P, N_{i}},
$$

then by differentiating (12) taking into account (13) and (14), we obtain the expression for a change in enthalpy during glass transition of supercooled melt:

$$
\Delta H_{\text {liq } \rightarrow \mathrm{am}}=R T \ln (1+\alpha) q(\tau)
$$

$q=-T \frac{\partial f(\tau)}{\partial T}= \begin{cases}a_{1} \tau^{-1}-3 a_{2} \tau^{3}-9 a_{3} \tau^{9}-15 a_{4} \tau^{15} & \text { при } \tau \leq 1 ; \\ 5 b_{1} \tau^{-5}+15 b_{2} \tau^{-15}+25 b_{3} \tau^{-25} & \text { при } \tau>1 .\end{cases}$

In Shao theory [18-20] the stabilization parameter $\alpha$ included in formulas (12) and (16) is described as a function of composition similarly to the Gibbs energy of a multi-component solution in CALPHAD approach [21]:

$$
\begin{gathered}
\alpha=\sum_{i} x_{i} \alpha_{i}+\sum_{i, j} x_{i} x_{j} \Lambda_{i j}+\sum_{i, j, k} x_{i} x_{j} x_{k} \Lambda_{i j k} ; \\
\Lambda_{i j}=\sum_{n}{ }^{n} \Lambda_{i j}\left(x_{i}-x_{j}\right)^{n}, \quad n \geq 0 ; \\
\Lambda_{i j k}=x_{i}{ }^{i} \Lambda_{i j k}+x_{j}{ }^{j} \Lambda_{i j k}+x_{k}{ }^{k} \Lambda_{i j k}, \quad i \neq j \neq k,
\end{gathered}
$$

where parameters $\Lambda_{i j}$ and $\Lambda_{i j k}, \quad i \neq j \neq k$ which are expressed by the Redl-Kister-Muggianu polynomial, characterize binary a ternary interaction of atoms.

Glass transition temperature $T_{\mathrm{g}}$ of a multicomponent phase is determined in the same way:

$$
\begin{gathered}
T_{\mathrm{g}}=\sum_{i} x_{i} T_{\mathrm{g}, i}+\sum_{i, j} x_{i} x_{j} \Omega_{i j}+\sum_{i, j, k} x_{i} x_{j} x_{k} \Omega_{i j k} ; \\
\Omega_{i j}=\sum_{n}{ }^{n} \Omega_{i j}\left(x_{i}-x_{j}\right)^{n}, \quad n \geq 0 ; \\
\Omega_{i j k}=x_{i}{ }^{i} \Omega_{i j k}+x_{j}{ }^{j} \Omega_{i j k}+x_{k}{ }^{k} \Omega_{i j k}, \quad i \neq j \neq k,
\end{gathered}
$$

where $T_{\mathrm{g} i}$ is Kauzmann temperature for pure $i$-th component.

Thus, Gibbs energy and enthalpy of the amorphous phase are related to the corresponding values for the melt at the same temperature:

$$
G_{\mathrm{am}}=G_{\mathrm{liq}}+\Delta G_{\mathrm{liq} \rightarrow \mathrm{am}}, \quad H_{\mathrm{am}}=H_{l}+\Delta H_{\mathrm{liq} \rightarrow \mathrm{am}} .
$$

To use Shao theory it is necessary to determine Gibbs energy $G_{\text {liq }}$ and enthalpy $H_{\text {liq }}$ of liquid phase in (20). Within the CALPHAD approach [21] they are described as follows:

$$
\begin{gathered}
G_{\mathrm{liq}}=\sum_{i=1}^{k} x_{i} G_{i}^{l}+G_{\mathrm{id}}+H_{\mathrm{ex}} ; \quad G_{\mathrm{id}}=-T S_{\mathrm{id}} ; \\
H_{\mathrm{liq}}=\sum_{i=1}^{k} x_{i} H_{i}^{\mathrm{liq}}+H_{\mathrm{ex}},
\end{gathered}
$$

where $G_{i}^{\text {liq }}$ and $H_{i}^{\text {liq }}$ are Gibbs energy and enthalpy of the $i$-th element in the liquid state, $H_{\mathrm{ex}}$ is excess enthalpy of mixing

$$
H_{e x}=\sum_{j>i=1}^{N} x_{i} x_{j} L_{i j}+\sum_{k>j>i=1}^{N} x_{i} x_{j} x_{k} L_{i j k}, \quad i \neq j \neq k,
$$

The parameters of pair $L_{i j}$ and triple $L_{i j k}$ interaction in the melt are described using the RedlichKister-Muggianu polynomials

$$
\begin{gathered}
L_{i j}=\sum_{n}{ }^{n} L_{i j}\left(x_{i}-x_{j}\right)^{n}, \quad i \neq j, \quad n \geq 0 ; \\
L_{i j k}={ }^{0} L_{i j k}+{ }^{i} L_{i j k} x_{i}+{ }^{j} L_{i j k} X_{j}+{ }^{k} L_{i j k} x_{k}, \quad i \neq j \neq k .
\end{gathered}
$$

\section{Partial molar quantities of components}

To determine the partial quantities of the components of the alloy (of chemical potential $\mu_{i}^{(\mathrm{am})}$ and partial molar enthalpy $h_{i}^{(\mathrm{am})}$ ) the following formula is used

$$
z_{i}^{(\mathrm{am})}=Z_{\mathrm{am}}+\sum_{j=2}^{N}\left(\delta_{i j}-x_{j}\right) \frac{\partial Z_{\mathrm{am}}}{\partial x_{j}},
$$

where $Z_{\mathrm{am}}$ is integral thermodynamic parameter, $Z_{\mathrm{am}} \equiv G_{\mathrm{am}}, H_{\mathrm{am}}, S_{\mathrm{am}}$, (Gibbs energy, enthalpy and entropy per $1 \mathrm{~mol}$ of the solution), $z_{i}^{(\mathrm{am})}$ is the corresponding partial molar value for the $i$-th component in this phase, $\delta_{i j}$ is Kronecker symbol: $\delta_{i j}=1$ at $i=j, \delta_{i j}=0$ at $i \neq j$. Here it is assumed that number $i=1$ is referred to alloy base (in this case $-\mathrm{Fe}$ ).

Thus, to determine the partial molar characteristic of any component of the amorphous phase it is necessary to perform differentiation of the corresponding integral parameter by concentrations of all components except the first one (Fe) taking into account that $x_{1} \equiv x_{\mathrm{Fe}}=1-\sum_{i=2}^{N} x_{i}$. At the same time for 
Shao model the derivatives of values $\Delta G_{\mathrm{liq} \rightarrow \mathrm{am}}$ (see formula (12)) and $\Delta H_{\mathrm{liq} \rightarrow \mathrm{am}}$ (see expression (16)) by the concentration of the $i$-th component have the following form:

$$
\begin{aligned}
& \frac{\partial \Delta G_{\mathrm{liq} \rightarrow \mathrm{am}}}{\partial x_{i}}=\frac{R T}{1+\alpha} f \frac{\partial \alpha}{\partial x_{i}}+R T \ln (1+\alpha) p, p=\frac{\partial f}{\partial x_{i}} ; \\
& \frac{\partial \Delta H_{\mathrm{liq} \rightarrow \mathrm{am}}}{\partial x_{i}}=\frac{R T}{1+\alpha} q \frac{\partial \alpha}{\partial x_{i}}+R T \ln (1+\alpha) r, r=\frac{\partial q}{\partial x_{i}} .
\end{aligned}
$$

\section{The Calculation Results and Discussion}

When calculating Gibbs energy and enthalpy of stabilizing the amorphous phase by Shao model (see formulas (12), (13), (16) and (17)), component glass transition temperature $T_{\mathrm{g} i}$ for $\mathrm{Fe}, \mathrm{Ni}, \mathrm{Co}, \mathrm{Si}$ and $\mathrm{B}$, as well as parameters $\Lambda_{i j}$ and $\Lambda_{i j k}$ appearing in expressions (18) and values $\Omega_{i j}$ and $\Omega_{i j k}$, appearing in formulas (19), were taken from [18-20, 22]. Since there are nо $\Lambda$ и $\Omega$ values in the literature, for a number of components they were assumed to be equal to zero. Values $T_{\mathrm{g} i}$ for $\mathrm{Cr}$ and Mo were defined as $T_{\mathrm{g} i}=0.25 T_{\mathrm{m} i}$, where $T_{\mathrm{m} i}$ is the melting point of the $i$-th element. To calculate Gibbs energy $G_{\text {liq }}$ and enthalpy $H_{\text {liq }}$ of the multi-component liquid phase (see expressions (20) - (24)), we used the parameter values of pair $L_{i j}$ and triple $L_{i j k}$ interaction of the components of metal melts according to the data [23], as well as the data of numerous works on the calculation of binary and triple equilibrium state diagrams by CALPHAD

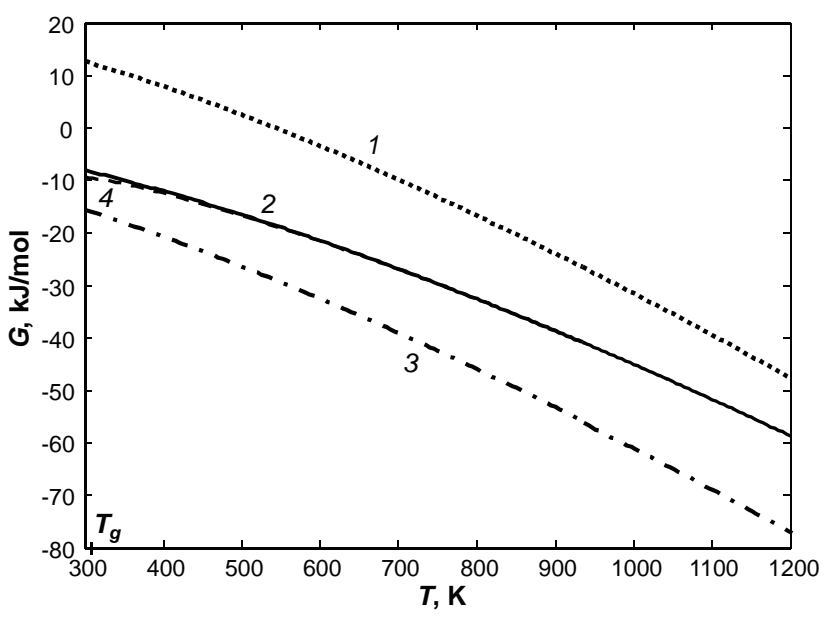

a) method. In this paper we present the results of calculations for alloy 1 .

To compare the values of integral and partial molar thermodynamic characteristics of the amorphous phase according to Shao and Miedema theories it was assumed that the composition of the amorphous phase corresponds to the total composition of alloy 1, i.e. it is $100 \%$ amorphous (we ignore the presence of $2 \%$ of crystalline inclusions).

Figure 1 shows temperature dependences of Gibbs energy and enthalpy of the amorphous phase for composition 1; for comparison it shows data for supercooled liquid iron and melt of composition 1 and value $T_{\mathrm{g}}$.

According to Fig. 1, Gibbs energy and enthalpy of supercooled four-component melt have significantly lower values than those of pure iron, which is explained by the presence of excess enthalpy of mixing $H_{\text {ex }}$ (see formula (21)). Miedema model over the entire temperature range gives lower values $G_{\text {am }}$ and $H_{\mathrm{am}}$ than Shao model, however, at room temperature $(300 \mathrm{~K})$ the difference in free energy does not exceed $8 \mathrm{~kJ} / \mathrm{mol}$ (see Fig. $1 \mathrm{a}$ ). According to Shao model, value $G_{\text {am }}$ falls below Gibbs energy of melt $G_{\text {liq }}$ at $T<500 \mathrm{~K}$, i.e. the conversion of supercooled melt into the amorphous phase becomes thermodynamically favorable. Also, according to this model, $H_{\mathrm{am}}<H_{\text {liq }}$ at $T<750 \mathrm{~K}$, and as the temperature falls to $T_{\mathrm{g}}=307 \mathrm{~K}$ this value reaches the value calculated by the Miedema model.

The calculation of chemical potential and partial molar enthalpy of iron in the amorphous phase of

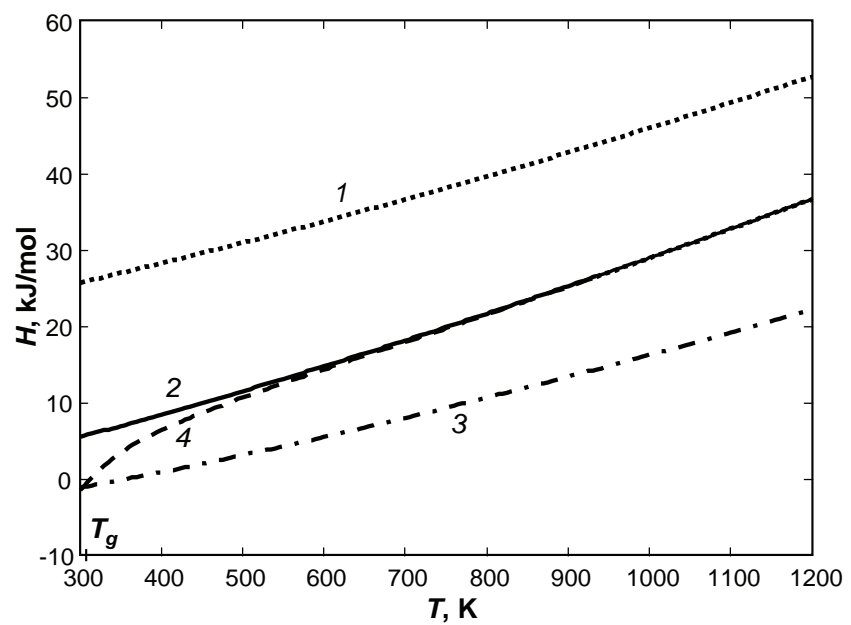

b)

Fig. 1. The dependence of Gibbs energy ( $a$ ) and enthalpy $(b)$ phases for composition 1 on temperature: 1 - pure liquid iron; 2 - supercooled melt; 3 - amorphous phase by Miedema model; 4 - amorphous phase by Shao model 


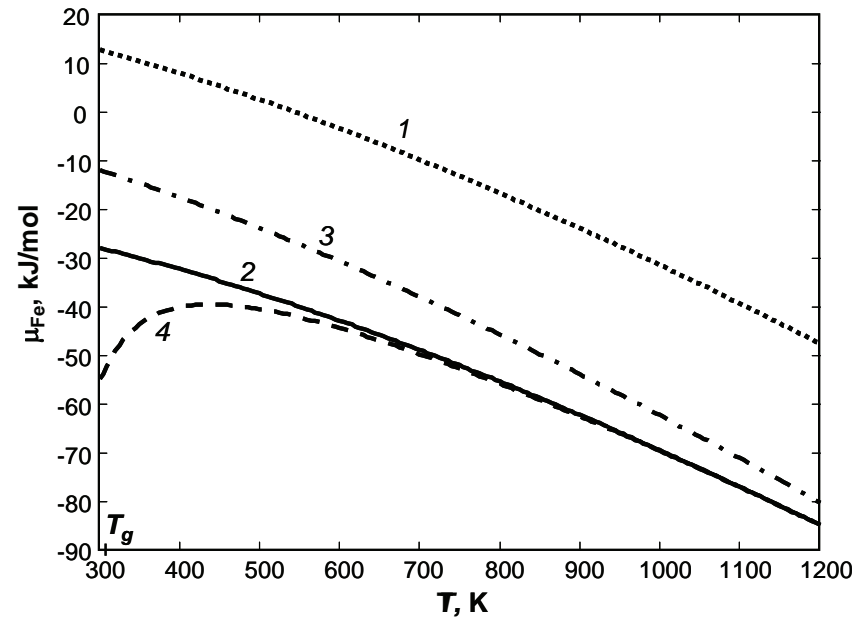

a)

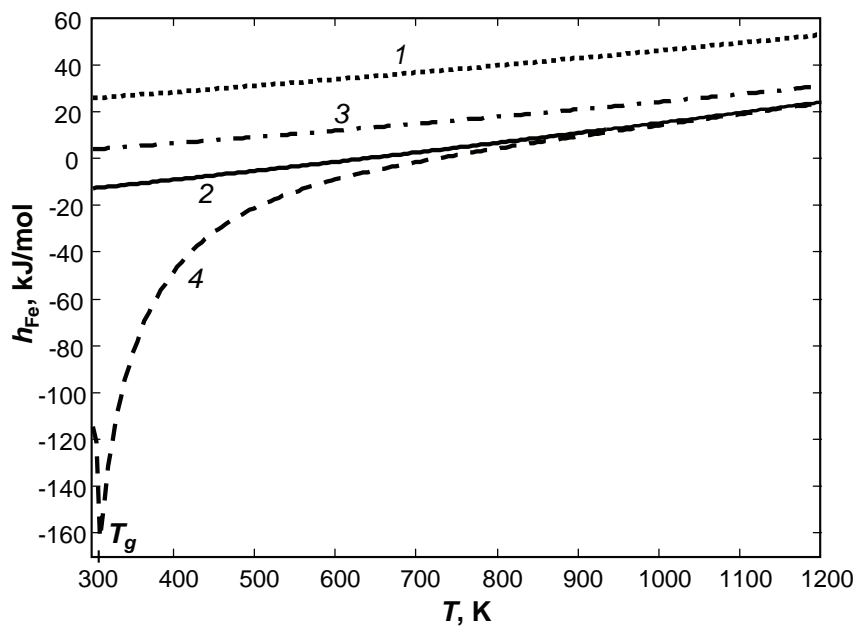

b)

Fig. 2. Temperature dependences of chemical potential of iron $(a)$ and its partial molar enthalpy $(b)$ in various phases for composition 1 :

1 - pure liquid iron; 2 - supercooled melt; 3 - amorphous phase by Miedema model; 4 - amorphous phase by Shao model

composition 1 according to two theories is presented in Fig. 2.

Figure 2 shows that Miedema model gives significantly higher values of both $\mu_{\mathrm{Fe}}^{(\mathrm{am})}$ and $h_{\mathrm{Fe}}^{(\mathrm{am})}$ than Shao model. At the same time, for $T<750 \mathrm{~K}$ chemical potential of iron in the amorphous phase according to Shao model is somewhat lower than in a supercooled melt, and as it approaches point $T_{\mathrm{g}}$ value $\mu_{\mathrm{Fe}}^{(\mathrm{am})}$ decreases by $15 \mathrm{~kJ} / \mathrm{mol}$ compared with the value at $500 \mathrm{~K}$ (see Fig. $1 \mathrm{a}$ ). When temperature decreases the most significant change is observed in

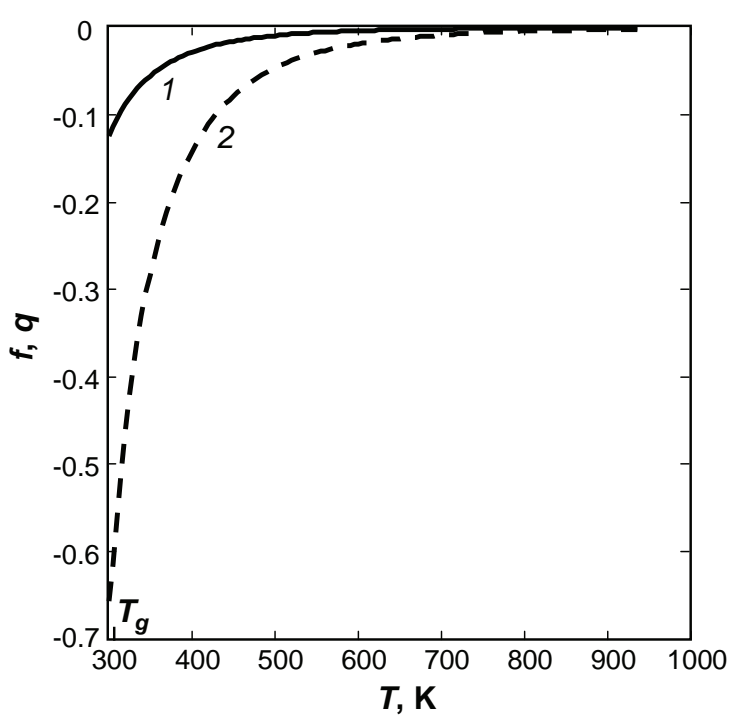

a) value $h_{\mathrm{Fe}}^{(\mathrm{am}))}$ in Shao model (Fig. $1 b$ ): as it approaches Kauzmann temperature $T_{\mathrm{g}}$ it decreases sharply (from $10 \mathrm{~kJ} / \mathrm{mol}$ at $600 \mathrm{~K}$ to $160 \mathrm{~kJ} / \mathrm{mol}$ ), and then it rises sharply up to $118 \mathrm{~kJ} / \mathrm{mol}$ at $300 \mathrm{~K}$. Such a type of curves $\mu_{\mathrm{Fe}}^{(\mathrm{am})}$ and $h_{\mathrm{Fe}}^{(\mathrm{am})}$ for this composition of the amorphous phase is due to temperature dependence of parameters $p$ and $r$ in equations (26) which arise when differentiating expressions for $\Delta G_{\mathrm{liq} \rightarrow \mathrm{am}}$ and $\Delta H_{\mathrm{liq} \rightarrow \mathrm{am}}$ in Shao theory.

These functions are shown in Fig. 3 where, for clarity, you can see functions $f(\tau)$ (see formula (13))

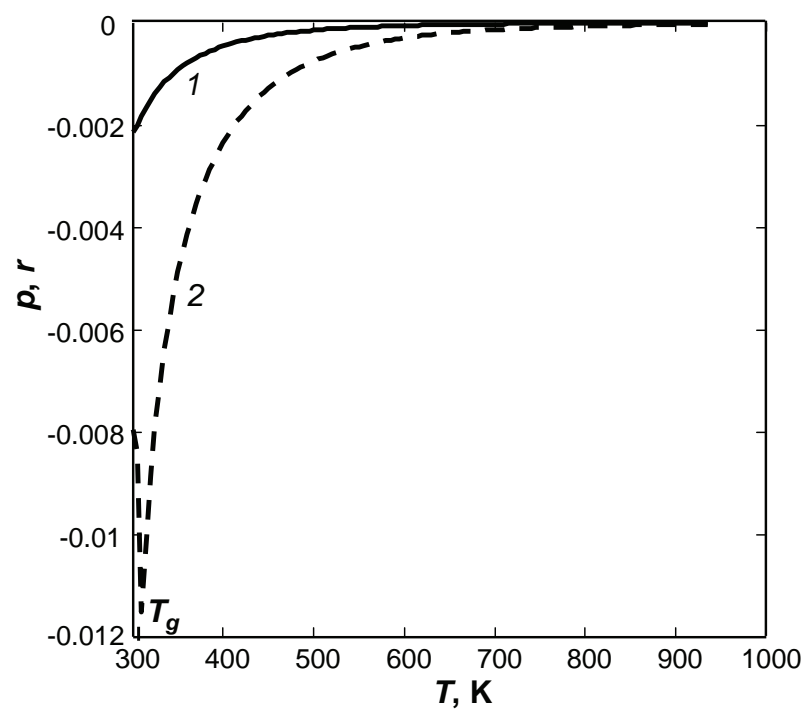

b)

Fig. 3. Temperature dependences of Shao model parameters for amorphous phase 1:

$a-f$ (line 1) and $q$ (line 2) to calculate the integral thermodynamic quantities (Gibbs energy and enthalpy, respectively); $b-p$ (line 1) and $r$ (line 2) to calculate the partial molar quantities (chemical potential and partial enthalpy, respectively) 
and $q(\tau)$ (see formula (17)) where $\tau=T / T_{\mathrm{g}}$. At the same time, value $r$ included in the expressions for the partial molar enthalpy of the components of the amorphous phase, has a sharp minimum at $T=T_{\mathrm{g}}$ (see Fig. $3 b$ ). The latter leads to the presence of a minimum on temperature dependence $h_{\mathrm{Fe}}^{(\mathrm{am})}$ (see Fig. $2 b$ ).

From physical considerations the partial molar characteristics (chemical potential and partial enthalpy) of the base element are unlikely to change greatly in a narrow range of temperature in the region of stability of the amorphous phase. According to experimental data, with a slight change in temperature around the room one $( \pm 10 \mathrm{~K})$ measured value $\Delta \mu_{\mathrm{M}}$ remained almost unchanged. Therefore, a strong change in the calculated values $\mu_{\mathrm{Fe}}^{(\mathrm{am})}$ (Fig. $2 a$ ) and especially $h_{\mathrm{Fe}}^{(\mathrm{am})}$ (Fig. $2 b$ ) in a narrow range of temperature is an artefact due to the fact that Shao model [18-20] structurally is designed to evaluate the integral thermodynamic parameters $G_{\mathrm{am}}$ and $H_{\mathrm{am}}$ and is not suitable for the correct description of the partial molar quantities of elements in a multicomponent amorphous phase.

Figure 4 shows a comparison of the calculated values $\mu_{\mathrm{Fe}}{ }^{(\mathrm{am})}$ and $h_{\mathrm{Fe}}{ }^{\text {(am) }}$ for the amorphous phase of alloy 1 , obtained according to two models, with the quantities obtained in our previous work [8] on the basis of experimental measurements for different MA

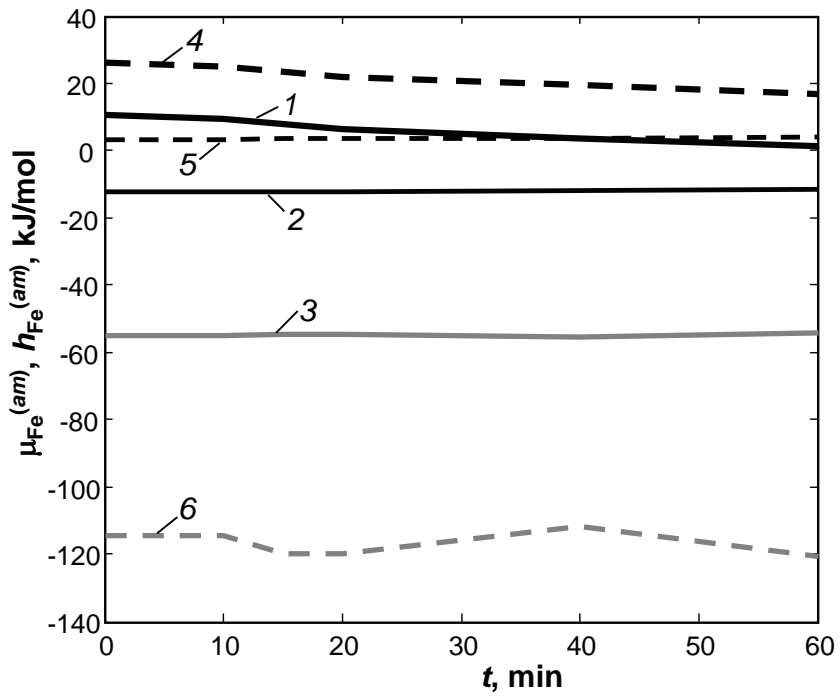

Fig. 4. Chemical potential $\mu_{\mathrm{Fe}}^{(\mathrm{am})}$ (lines $1-3$ ) and partial molar enthalpy of iron $h_{\mathrm{Fe}}^{(\mathrm{am})}$ (lines $4-6$ ) in the amorphous phase of alloy 1 defined on the basis of the experiment for different MA times (lines 1 and 4) [8] and calculated by Miedema model (lines 2 and 5) and Shao model (lines 3 and 6) at a room temperature times in attritor $t$. A decrease in the experimental values $\mu_{\mathrm{Fe}}^{(\mathrm{am})}$ (line 1) and $h_{\mathrm{Fe}}^{(\mathrm{am})}$ (line 4) with MA time results from both dissolving the crystalline phases and a change in atomic-cluster structure of the amorphous phase under periodic plastic deformation. The latter factor is not taken into account in the thermodynamic Miedema and Shao models, therefore the corresponding estimated partial molar quantities do not change in time.

From Fig. 4 it is seen that theoretical values $\mu_{\mathrm{Fe}}^{(\mathrm{am})}$ and $h_{\mathrm{Fe}}^{(\mathrm{am})}$ significantly differ from the values determined on the basis of experimental data, Shao model (line 3 for $\mu_{\mathrm{Fe}}^{(\mathrm{am})}$ and line 6 for $h_{\mathrm{Fe}}^{(\mathrm{am})}$ giving a rather significant deviation from the experiment. Fluctuations of values $h_{\mathrm{Fe}}^{(\mathrm{am})}$ according to Shao model (line 6) are related to the fact that the composition of the amorphous phase and value $T_{\mathrm{g}}$ which depends on it change when crystalline inclusions dissolve. Since for the amorphous phase of alloy 1 Kauzmann temperature is to close to a room temperature, small variations in its composition and value $T_{\mathrm{g}}$ lead to fluctuations in parameter $r$ and consequently to a noticeable change 1 in $h_{\mathrm{Fe}}^{(\mathrm{am})}$ (by $\approx 10 \mathrm{~kJ} / \mathrm{mol}$ ).

\section{Conclusion}

Thus, in this study it is shown that the existing thermodynamic theories of amorphous state (Miedema and Shao models) give similar values of integral quantities $G_{\mathrm{am}}$ and $H_{\mathrm{am}}$ for the amorphous alloy with composition 1 at a room temperature, but the values of the partial molar quantities according to these two theories differ considerably. Moreover, the calculated data demonstrate a large deviation from values $\mu_{\mathrm{Fe}}^{(\mathrm{am})}$ and $h_{\mathrm{Fe}}^{(\mathrm{am})}$ defined on the basis of electrochemical measurements, and this error is very significant for Shao model.

This is due to the fact that Miedema and Shao models were developed for the theoretical estimation of integral thermodynamic parameters (enthalpy and Gibbs energy) and are not designed to determine the partial molar quantities of elements in the multicomponent amorphous phase (chemical potentials and partial enthalpy). The development of new thermodynamic models for amorphous solids for physically correct description of their partial molar characteristics is a very complex task and requires further research. 


\section{References}

1. Kovalenko N.P., Krasny Yu.P., Krey U. Physics of Amorphous Metals. WILEY-VCH, 2001, $280 \mathrm{pp}$.

2. Suryanarayana C., Inoue A. Bulk Metallic Glasses. CRC Press, 2011, 523 pp.

3. Schroder H., Samwer K. Micromechanism for metallic-glass formation by solid-state reactions. Phys. Rev. Lett., 1985, vol. 54, no. 3, pp. 197-200.

4. Gallego L.J., Somoza J.A., Alonso J.A. Glass formation in ternary transition metal alloys. J. Phys.: Condens. Matter, 1990, vol. 2, pp. 6245-6250.

5. Zhang B., Jesser W.A. Formation energy of ternary alloy systems calculated by an extended Miedema model. Physica B: Cond. Matter, 2002, vol. 315, no. 1-3, pp. 123-132.

6. Kutsenok I.B., Solomonova I.V., Tomilin I.A. Termodinamicheskaya stabilnost amorfnyih metallicheskih splavov [The thermodynamic stability of the amorphous metal alloys]. Zhurn. fiz. Himii [J. Phys. Chem.], 1992, vol. 66, no.12, pp. 3198-3204. (Rus)

7. Vasileva O.Ya., Kutsenok I.B., Tomilin I.A., Geydrih V.A. Termodinamicheskie svoystva amorfnyih splavov sistemyi Co-Fe-Si- [Thermodynamic properties of amorphous alloy system Co-Fe-Si]. Zhurn. fiz. Himii [J. Phys. Chem.], 1993, vol. 67, no. 6, pp. 11531155. 9 (Rus)

8. Khina B.B., Goranskiy G.G. Thermodynamic properties of multicomponent amorphous alloys in systems Fe-Si-B-Ni and Fe-Si-B-Ni-Co-Cr-Mo. Adv. Mater. \& Technol., 2016, no. 2, pp. 8-15.

9. Van der Kolk G.J., Miedema A.R., Niessen A.K. On the composition range of amorphous binary transition metal alloys. J. Less-Common Met., 1988, vol. 145, pp. 1-17.

10. Weeber A.W., Loeff P.I., Bakker H. Glassforming range of transition metal-transition metal alloys prepared by mechanical alloying. J. LessCommon Met., 1988, vol. 145, pp. 293-299.
11. Loeff P.I., Weeber A.W., Miedema A.R. Diagrams of formation enthalpies of amorphous alloys in comparison with the crystalline solid solution. J. Less-Common Met., 1988, vol. 140, pp. 299-305.

12. Miedema A.R., de Chatel P.F., de Boer F.R. Cohesion in alloys - fundamentals of a semi-empirical model. Physica B., 1980, vol. 100, pp. 1-28.

13. Miedema A.R. The electronegativity parameter for transition metals: Heat of formation and charge transfer in alloys. J. Less-Common Met., 1973, vol. 32, pp. 117-136.

14. de Boer F.R., Boom R., Mattens W.C.M., Miedema A.R., Niessen A.K. Cohesion in Metals: Transition Metal Alloys. Elsevier, 1988, 758 p.

15. Dinsdale A.T. SGTE data for pure elements. Calphad, 1991, vol. 15, pp. 317-425.

16. Mansoori G.A., Carnahan N.F., Starling K.E., Leland T.W., jr. Equilibrium thermodynamic properties of the mixture of hard spheres. J. Chem. Phys., 1971, vol. 54, pp. 1523-1525.

17. Takeuchi A., Inoue A. Calculations of mixing enthalpy and mismatch entropy for ternary amorphous alloys. Mater. Trans. JIM., 2000, vol. 41, pp. 1372-1378.

18. Shao G. Prediction of amorphous phase stability in metallic alloys. J. Appl. Phys., 2000, vol. 88, no. 7, pp. 4443-4445.

19. Liu Y.Q., Shao G., Homewood K.P. Prediction of amorphous phase stability in the metalsilicon systems. J. Appl. Phys., 2001, V.90, No. 2, pp. 724-727.

20. Shao G. Thermodynamic and kinetic aspects of intermetallic amorphous alloys. Intermetallics, 2003, vol. 11, no. 4, pp. 313-324.

21. Lukas H.L., Fries S.G., Sundman B. Computational Thermodynamics: The Calphad Method. Cambridge University Press, 2007, 313 p.

22. Poletti M.G., Battezzati L. Assessment of the ternary Fe-Si-B phase diagram. Calphad, 2013, vol. 43. pp. 40-47.

23. Miettinen J. Approximate thermodynamic solution phase data for steels. Calphad, 1998, vol. 22, pp. 275-300. 